\title{
EL ACUERDO DE LIBRE COMERCIO ENTRE ESTADOS UNIDOS Y CANADA: ALGUNAS LECCIONES
}

\author{
Hamish I. Stewart Stokes
}

\begin{abstract}
El Acuerdo de Libre Comercio (FTA) entre Canadá y Estados Unidos estableció las bases para la posterior creación del Area de Libre Comercio de Norteamérica (NAFTA). De ahí que Chile, a pesar de las diferencias económicas y geográficas, puede aprender de la experiencia canadiense, debido a que existen similitudes en sus posiciones para la negociación de un acuerdo de libre comercio con Estados Unidos. Así, se analiza el trasfondo de la decisión canadiense en buscar un acuerdo de este tipo, los puntos y objetivos esenciales de sus negociadores y los resultados, además de los efectos del primer tiempo de operación. Finalmente, se mencionan las principales lecciones para Chile: la obtención de un mecanismo aceptable para la solución de disputas comerciales; aprovechar la cláusula de advenimiento de NAFTA, en lugar de intentar bilateralmente un nuevo acuerdo; la búsqueda de diversos apoyos dentro de Estados Unidos, estableciendo fechas límites y negociando hábilmente.
\end{abstract}

El 17 de marzo de 1985, el Presidente de los Estados Unidos Ronald Reagan y el Primer Ministro de Canadá Brian Mulroney, declararon que se estaban embarcando "en un mutuo esfuerzo para establecer un clima de mayor predicción y confianza para que canadienses y americanos en conjunto puedan planificar, invertir, crecer y competir con más efectividad los unos con los otros y en el mercado global". ${ }^{1}$ En poco menos de cuatro años los dos gobiernos aprobaron el Acuerdo de Libre Comercio entre Canadá y los Estados Unidos (FTA), que estará funcionando completamente en 1998. Este Acuerdo probablemente es uno de los logros más importantes de ambos líderes.

Menos de dos años después de la aprobación del Acuerdo, el 11 de junio de 1990, el Presidente mexicano Carlos Salinas de Gortari y el Presidente de los Estados Unidos George Bush emitieron una declaración casi idéntica, comprometiendo a sus dos gobiernos a la

\footnotetext{
${ }^{1}$ Hart, A North American Free Trade Agreement, p. 1.
} 
negociación de un acuerdo bilateral universal de comercio. Canadá, no obstante sus sospechas acerca de los intentos de los norteamericanos de renegociar ciertas cláusulas de su acuerdo, decidió participar en estas negociaciones. El resultado fue la conclusión, el 17 de agosto de 1992, después de 14 meses de arduas negociaciones, de un Acuerdo entre Estados Unidos, Canadá y México que creará, una vez aprobada por las legislaturas de los tres países, el Area de Libre Comercio de Norteamérica (NAFTA).

El FTA estableció las bases para las negociaciones que produjeron a NAFTA. Gran parte del nuevo tratado es una copia simple del anterior, mientras que adonde se han introducido cambios, éstos han sido principalmente para mejorar cláusulas y sistemas ya establecidos. Posiblemente, el cambio más interesante entre los dos tratados, desde el punto de vista chileno, es que NAFTA incluye una cláusula de advenimiento que suministrará un proceso por el cual otros países del hemisferio occidental podrán unirse a la zona de libre comercio, sin la necesidad de largas y complicadas negociaciones con cada uno de los tres socios. ${ }^{2}$

Chile ya firmó un acuerdo de libre comercio con México y ha expresado su interés en negociar un acuerdo similar con los Estados Unidos. Tanto la Representante para el Comercio de los Estados Unidos Carla Hills, como el Presidente Bush, anunciaron que las negociaciones con Chile tendrían que esperar el resultado de las que se efectuaran con México, pero que en cualquier caso se basarían en el acuerdo a que finalmente se hubiera llegado con México. ${ }^{3}$ Entonces, la experiencia canadiense en negociar un acuerdo de este tipo con los Estados Unidos, puede ser de gran relevancia para Chile.

Aunque no quiero ignorar las diferencias económicas y geográficas indudables entre Chile y Canadá, este trabajo sostiene que hay bastantes similitudes entre las posiciones de ambos países en lo que concierne a los Estados Unidos (por ejemplo, las economías de ambos países dependen de la exportación de materias primas), para que sea beneficioso examinar: primero, el trasfondo de la decisión canadiense de buscar un acuerdo de libre comercio; segundo, aquellos puntos que los negociadores canadienses consideraron de vital importancia durante las negociaciones; $y$, finalmente, los resultados

\footnotetext{
${ }^{2}$ The Giobe and Mail, "North America agrees to deal", 13 de agosto de 1992.

${ }^{3}$ The Economist, "The Business of the American Hemisphere", 24 de agosto de 1991 y "Shoot-out at Jackson Hole", 31 de agosto de 1991.
} 
de las negociaciones, incluyendo los efectos de los primeros dos años de operación del Acuerdo.

Tradicionalmente, Canadá siempre ha sido ambivalente acerca de la idea de establecer lazos más cercanos con los Estados Unidos. Ha habido por lo menos nueve proyectos de libre comercio parcial o universal entre ambos países durante los últimos 130 años. Algunos fueron marcados por controversias públicas y ásperas; otros fueron juzgados y aceptados tranquilamente. Algunos fueron iniciados por los Estados Unidos; pero más fueron los que inició Canadá. Durante todas las discusiones en Canadá sobre el libre comercio, la duda sobre sus implicaciones políticas generalmente se ha puesto en primer plano. El balance entre las razones económicas y las consecuencias políticas ha cambiado durante el intermitente debate según la naturaleza de la propuesta y las circunstancias que las produjo. Así que las implicaciones del libre comercio, su "significado interior" toca las raíces más profundas de la existencia nacional de Canadá. Los debates sobre el libre comercio se han llamado discusiones simbólicas sobre la naturaleza y destino de Canadá. ${ }^{4}$

El Dominio de Canadá se creó en 1867 en parte como reacción a la abrogación por los Estados Unidos del Tratado de Reciprocidad que funcionaba entre 1854 y 1866 . El sueño de un regreso a aquella "edad de oro" no murió, aun después de que Canadá tomó forma. El Primer Ministro John A. Macdonald lo persiguió muchas veces en lo que parecían ser momentos oportunos. Finalmente fue obligado a admitir la derrota y asumir el modelo proteccionista que los Estados Unidos había escogido después de la Guerra Civil. Esta Política Nacional, introducida en 1879 , buscó producir el desarrollo económico y una industria manufacturera en Canadá a través de una combinación de altos aranceles, desarrollo de infraestructura y politicas de inmigración. Los elementos de política de comercio exterior fueron continuamente ajustados en el transcurso de los años pero hasta los años cincuenta, Canadá nunca se alejó de los objetivos gemelos de desarrollar industrias que sustituían importaciones por medio de niveles altos de protección mientras buscaba el acceso a mercados extranjeros para sus materias primas abundantes. ${ }^{5}$

La oposición a los acuerdos de libre comercio siempre ha sido política, basada en lo que se conoce como el argumento de la "cuesta

\footnotetext{
${ }^{4}$ Farr, "Inner Meaning of Free Trade", International Perspectives, Vol. XVII, Ne4, pp. 3-7.

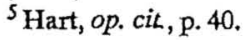


resbaladiza": que una unión económica más cercana llevaría inevitablemente a una unión política. Este argumento fue suficiente para asegurar la derrota del Partido Liberal, que favorecía la reciprocidad en las elecciones federales de 1891 y 1911, y no estuvo ausente del debate sobre el acuerdo de libre comercio que dominó a las elecciones federales de 1988. Un ejemplo de los cambios que han ocurrido en Canadá es el hecho de que esta vez el argumento no funcionó.

Desde 1911 a 1985 el libre comercio con los Estados Unidos no fue un tópico de debate amplio en Canadá. Esto no significa que la idea del libre comercio hubiera desaparecido durante este período. Al contrario, fue puesta en acción sobre una base selectiva en por lo menos cinco ocasiones. Parece que hubiera dos razones por las cuales estas medidas no crearon las mismas preocupaciones que habían atemorizado a los canadienses en 1891 y 1911. Una razón fue el alcance limitado de estos arreglos comerciales; la única propuesta universal, el Acuerdo de Libre Comercio de 1948, murió en el gabinete canadiense. Era más fácil para los canadienses tragar una medida parcial de libre comercio. La segunda fue el hecho de que siempre habían razones claras y apremiantes para aplicar estos arreglos. Se podía considerarlos como medicamento para un enfermo en peligro. ${ }^{6}$

Los Tratados Comerciales de 1935 y 1938 , se alcanzaron durante la Gran Depresión que devastó a las exportaciones canadienses de materias primas, mientras que la Declaración de Hyde Park de 1941 fue parte de la incipiente alianza política y militar que se desarrolló durante la Segunda Guerra Mundial, y que llevó directamente a la integración sin paralelo que existe entre Canadá y los Estados Unidos hoy en día. El Acuerdo para Compartir la Producción de'Defensa de 1959 y el Acuerdo Automovilístico de 1965, fueron especializados en alcance y técnicas en su naturaleza aunque tuvieron efectos fenomenales sobre las exportaciones e importaciones de Canadá. ${ }^{7}$

Al mismo tiempo, Canadá participó en las siete rondas de negociaciones multilaterales llevadas a cabo bajo los auspicios del GATT, adonde muchas veces se acus 6 a Canadá de ser uno de los más hábiles explotadores de las negociaciones multilaterales mercantilistas. En las negociaciones multilaterales se comparte cualquier . concesión que se negocia entre dos Estados con todos los demás

\footnotetext{
${ }^{6}$ Farr, op. cit, p. 6.

7 Ibid, p. 7.
} 
participantes. Como resultado, se desarrolla una jerarquía en el proceso de negociación basada en el poder de mercado. Dependiendo del mayor número de concesiones que uno pueda hacer, probablemente uno recibirá un mayor número de concesiones. Entonces, particularmente mientras los aranceles fueron el principal instrumento de protección, los mayores acuerdos se concertaron entre los países europeos y entre ellos y los Estados Unidos. Cuando Europa empezó a regatear comó un todo y Japón se convirtió en una potencia económica, las negociaciones llegaron a ser triangulares. Cuando los Tres Grandes llegaron a Canadá, solamente los Estados Unidos tenía mucho interés. Así, Canadá se beneficiaba de los acuerdos entre los Tres Grandes, pero solamente tuvo que hacer concesiones en sus negociaciones bilaterales con los Estados Unidos. ${ }^{8}$

Esto significó que el sistema multilateral reforzaba en forma perversa la atracción de la geografía, una atracción que como se les dijo a los canadienses, solamente se podía resistir a través de negociaciones multilaterales. Como; resultado del sistema GATT, Canadá se estaba volviendo más, en vez de menos dependiente del mercado americano. Los intentos para diversificar las exportaciones canadienses y para alentar a sus compañías industriales de producir para el mercado internacional en vez de solamente el interno, fueron fracasos abyectos. El resultado fue que la industria manufacturera canadiense siguió siendo pequeña, fragmentada e ineficaz, concentrada en abastecer al mercado doméstico - una situación alentaḍa por los altos niveles de la protección arancelaria para bienes completamente procesados tanto de Canadá como de los Estados Unidos: La mayoría de las exportaciones canadienses se concentraban en recursos a niveles relativamente bajos de procesamiento o en productos automovilísticos quese beneficiaban del Acuerdo Automovilístico bilateral. ${ }^{9}$

El sistema GATT también permitió a Canadá perseguir una política de comercio orientada hacia el liberalismo en Ginebra, mientras se mantenía una mezcla de políticas domësticas mucho menos liberal. Todo esto se justificaba ideológicamente por medio de la afirmación de que debido al hecho de que Canadá era un país "pequeño" que dependía del comercio con países más grandes, estaba en una posición no igual y necesitaba tomar medidas para: defender

\footnotetext{
${ }^{8}$ Hart, op, cit, p. 41.

${ }^{9}$ Thomson, "Adjusting to Free Trade Challenges", Econoscope, 17 de julio de 1989, pp. 3-6; Wilson, Canada's Economic Prospects: Looking Ahead to the 19905, pp. 23-28.
} 
sus intereses y ayudar a su ventaja comparativa - un argumento propio de industrias jóvenes aplicado al país en total. Este argumento tenía gran atracción emocional pero poca base intelectual, porque en efecto negaba los cimientos básicos del sistema multilateral abierto, sistema que los funcionarios canadienses estaban entrenados para apoyar en el extranjero en tanto que se lo circunscribía en casa. ${ }^{10}$

La década de los ochenta fue una revolución para Canadá. Lo vieron abandonar finalmente la Política Nacional y adoptar políticas enfocadas en hacer al sector manufacturero más competitivo a nivel global a través de un comercio más libre. El FTA fue una parte central de esta política. Esto se debió a una evaluación pragmática de que las negociaciones multilaterales no suministraban suficientes garantías para la reestructuración significativa que las industrias canadienses tenían que llevar a cabo. Un escepticismo considerable sobre las posibilidades de éxito de la Ronda de Negociaciones sobre Comercio de Uruguay del GATT apuntaló la negociación del FTA.

Los puntos claves del Acuerdo que finalmente se concluyó son

1. Todos los aranceles entre Canadá y los Estados Unidos desaparecerán en un período de diez años.

2. Se incluyen servicios y energía además de bienes.

3. Debido a que el comercio y la inversión son complementarios, se liberalizan los flujos de inversión. La inclusión de servicios e inversiones hace que este acuerdo sea absolutamente nuevo.

4. Se estableció un mecanismo para resolver disputas binacionales con el objeto de ayudar a eliminar motivos y factores políticos del proceso para resolver disputas comerciales.

5. Se agilizan los trámites para los viajes de negocios entre los dos países, ayudando así a flexibilizar el capital humano. ${ }^{11}$

Canadá tuvo tres objetivos fundamentales para negociar este acuerdo. Quizás el más importante, pero inđudablemente el menos publicitado, fue el de llevar a cabo reformas domésticas, eliminando, por lo menos para el comercio con los Estados Unidos, los últimos vestigios de la Política Nacional y constriñendo los más sutiles nuevos instrumentos del proteccionismo. Fronteras más abiertas obligarían a las compañías canadienses a reestructurarse y modernizarse y volverse más eficientes y productivas, a fin.de que estuvieran listas

\footnotetext{
${ }^{10}$ Hart, op. cit, p. 45.

${ }^{11}$ Econoscope, "Free Trade Agreement: One year retrospective", p. 3; Extemal Affairs Canada, "The Text of the Canada-U.S. Frec Trade Agreement".
} 
para competir en el resto del mundo, sin esperar a que la Ronda de Uruguay lograra o no relajar las restricciones al comercio alrededor del mundo. ${ }^{2}$ ?

Al mismo tiempo, eventualmente este acuerdo permitirá o incluso obligará al gobierno federal y los provinciales, a eliminar las muchas restricciones y programas que impiden el comercio y la asignación eficiente de los recursos. Ejemplos de sólo algunọs de ellos son los sistemas especiales de avalúo y clasificación que Canadá empleaba hasta 1988 - que eran poderosas barreras no-arancelarias y los sistemas discriminatorios de distribución de vino y cervezas que protegen de la competencia extranjera a los cerveceros y viñateros canadienses. También los contratos gubernamentales discriminatorios hacen impiosible que compitan tanto las compañías extranjeras como las compañías de otras provincias. Más y más las diferentes provincias han establecido barreras entre sí, que no solamente afectan al comercio internacional, sino también al comercio intraprovincial. Políticamente es casi imposible atacar estas prácticas directamente, pero los negociadores canadienses esperaban que el Tratado, por medio de una competencia aumentada y la presión de los Estados Unidos, llevaría a cabo reformas por la fuerza, fuesen deseadas o no. 13

El objetivo más publicitado fue el de proporcionar una barrera en contra del proteccionismo norteamericano. Considero que este objetivo es el que más interesa a Chile. Al confirmar el FTA el movimiento de Canadá hacia una política comercial orientada hacia el mercado, detuvo la deriva de los Estados Unidos hacia más protección, por lo menos en lo que concierne a Canadá. En los años inmediatamente después de la guerra, los funcionarios norteamericanos se jactaban de que Estados Unidos tenía el mercado más abierto del mundo. Una administración tras otra actuó para lograr que el sistema comercial mundial fuera más abierto. Se ha mantenido la retórica, aunque la realidad ha cambiado. Estados Unidos havuelto a su posición proteccionista histórica (Ver Cuadro 1). ${ }^{1.4}$

\footnotetext{
${ }^{12}$ Econascope, ibid., pp. 15-21.

${ }^{13}$ Hart, op. cit, p. 44.

${ }^{14}$ Ibid, pp. 51-52.
} 


\begin{tabular}{|c|c|c|c|c|}
\hline \multicolumn{5}{|c|}{ Cuadro I: Principales Leyes Comerciales Reparadoras } \\
\hline Ley & Enfoque & Criterio & $\begin{array}{l}\text { Pemedlos } \\
\text { Disponibles }\end{array}$ & Autoridadea \\
\hline $\begin{array}{l}\text { Soc. } 201 \\
\text { "cláusula } \\
\text { de osca- } \\
\text { po" }\end{array}$ & Importaclones dafinas & $\begin{array}{l}\text { aumentos de Importa- } \\
\text { clones son una causa } \\
\text { sustancial do serlos } \\
\text { danos }\end{array}$ & $\begin{array}{l}\text { aranceles; cuotina; } \\
\text { cuotes arancelarlas; } \\
\text { axistencia de ajuste; } \\
\text { arreglos pare merca- } \\
\text { dos }\end{array}$ & $\begin{array}{l}\text { USrTC } \\
\text { Presidentea }\end{array}$ \\
\hline Sec. 701 & $\begin{array}{l}\text { Importaciones subven- } \\
\text { clonadas }\end{array}$ & danos materiales $b$ & $\begin{array}{l}\text { arancelos compensa- } \\
\text { torios }\end{array}$ & $\begin{array}{l}\text { USrTC } \\
\text { ITA }\end{array}$ \\
\hline Sec. 731 & $\begin{array}{l}\text { dumping (vender a un } \\
\text { procio menor que ol } \\
\text { precio justo) }\end{array}$ & danos materlates & aranceles anthamping & $\begin{array}{l}\text { USTC } \\
\text { nA }\end{array}$ \\
\hline Sec. 301 & $\begin{array}{l}\text { violaciones de acuer- } \\
\text { dos comerciales y com- } \\
\text { promtaos }\end{array}$ & $\begin{array}{l}\text { acclones son Irrazo-na- } \\
\text { bles o discriminatorias }\end{array}$ & $\begin{array}{l}\text { "todas las acclonos } \\
\text { apropriadas y factibles" }\end{array}$ & $\begin{array}{l}\text { USTR } \\
\text { Presidente }\end{array}$ \\
\hline Sec. 337 & $\begin{array}{l}\text { métodos comerciaies } \\
\text { Injustos (V.g. Usurpa- } \\
\text { clón de patentes o } \\
\text { marcas comerclales) }\end{array}$ & $\begin{array}{l}\text { acciones que destruyen } \\
\text { o dañan sustanclai- } \\
\text { mento a una industria. }\end{array}$ & $\begin{array}{l}\text { ódenes de exclusión, } \\
\text { órdenes de cesar y do- } \\
\text { sistlr }\end{array}$ & $\begin{array}{l}\text { USTC } \\
\text { Prosidento }\end{array}$ \\
\hline Sec. 338 & $\begin{array}{l}\text { discriminación por un } \\
\text { pás oxtranjoro }\end{array}$ & $\begin{array}{l}\text { una carga o desventala } \\
\text { para ol comerclo do } \\
\text { EE.UU. }\end{array}$ & $\begin{array}{l}\text { gumentar aranceles, } \\
\text { cuotas }\end{array}$ & $\begin{array}{l}\text { USTC } \\
\text { USOA } \\
\text { Presidente }\end{array}$ \\
\hline Sec. 22 & $\begin{array}{l}\text { Importaclones agrico- } \\
\text { las por dobajo do los } \\
\text { proclos on EE.UU. }\end{array}$ & $\begin{array}{l}\text { Interferencia con los } \\
\text { programas de apoyo a } \\
\text { los prectos }\end{array}$ & $\begin{array}{l}\text { derechos de importa- } \\
\text { ción, cuotas }\end{array}$ & $\begin{array}{l}\text { USTTC } \\
\text { USDA } \\
\text { Prestonto }\end{array}$ \\
\hline Sec. 406 & $\begin{array}{l}\text { importaciones desor- } \\
\text { ganlzadoras de países } \\
\text { comunistas }\end{array}$ & $\begin{array}{l}\text { Una cause significativa } \\
\text { de daños materlales. }\end{array}$ & arancolos, cuotas & $\begin{array}{l}\text { USTTC } \\
\text { Prosidente }\end{array}$ \\
\hline Sec. 332 & $\begin{array}{l}\text { cualquier Irrltanto } \\
\text { comercial }\end{array}$ & $\begin{array}{l}\text { ofocto sobre la Industria. } \\
\text { ostadounidense }\end{array}$ & arancoles, cuotas & USTC \\
\hline Soc. 232 & $\begin{array}{l}\text { importaciones on au- } \\
\text { mento }\end{array}$ & $\begin{array}{l}\text { amenaze a la seguridad } \\
\text { nacional }\end{array}$ & $\begin{array}{l}\text { Investigación, una va- } \\
\text { rodiad de modidas res- } \\
\text { trictivas }\end{array}$ & $\begin{array}{l}\text { Comercio } \\
\text { Presidente }\end{array}$ \\
\hline \multicolumn{5}{|c|}{$\begin{array}{l}\text { TTA: International Trade Administration of the US Dopartment of Commerce } \\
\text { USDA: US Department of Agriculture } \\
\text { USTC: US International Trade Commission } \\
\text { USTR: Ofice of the US Trade Rpresentathe } \\
\text { a. EI Congreso puede anular decisiones del Presidente. } \\
\text { b. La prueba de dafos maleriales solemente so puede extender a paises que cumplen con clertos requisitos. }\end{array}$} \\
\hline
\end{tabular}

El proteccionismo tiene raíces profundas y duraderas en los Estados Unidos. Desde el Congreso Continental hasta el Arancel Smoot-Hawley de 1930, los legisladores estadounidenses protegieron a sus fabricantes de la competencia mundial. Los costos de este proteccionismo fueron una carga fácilmente soportable para una economía continental en expansión. Durante un período breve-desde la Ley de Acuerdos Comerciales Recíprocos de 1934 hasta las 
medidas económicas de Nixon de 1971-, Estados Unidos adoptó una política de comercio liberal que miraba hacia afuera a fin de avanzar sus intereses económicos y políticos mundiales. Pero, ya para los años setenta, las condiciones que habían permitido una política comercial liberal habían perdido fuerza y relevancia, y la política comercial norteamericana empezó a regresar a sus hábitos fundamentalmente proteccionistas. La baja en el apoyo a la política liberal fue paralela a la creciente exposición de la economía norteamericana al comercio mundial. ${ }^{15}$

Al entrar Estados Unidos a la década de los noventa, tres fuerzas compiten por la dirección de la política comercial norteamericana. Una, representa a la ortodoxia multilateral tradicional que abastecía al liderazgo de Estados Unidos en la construcción y mantención del sistema comercial multilateral y que impulsa la posición norteamericana en la Ronda de Uruguay. La segunda, es la reaparición del aislacionismo y proteccionismo desdeñoso y desconfiado del sistema comercial multilateral. La tercera, favorece la negociación de acuerdos regionales o bilaterales con países seleccionados -notablemente Canadá, México y aquellos del borde del Pacífico-, sea por sus propios méritos o como un complemento a la Ronda de Uruguay.

Canadá muchas veces se ha encontrado en el lado receptor de los usos arbitrarios de las mal llamadas "leyes remediales para el comercio" elaboradas por el Congreso estadounidense. No solamente se han aplicado estas leyes directamente a las exportaciones canadienses, sino muchas veces los productos canadienses han sido golpeados de refilón por acciones estadounidenses en contra de terceros países. Canadá, entonces, entró a las negociaciones para el FTA con la posición de que debiera estar exento de las leyes remediales estadounidenses, debido a que la potencialidäd para acciones arbitrarias aumentaría enormemente el riesgo de los hombres de negocios canadienses, que comprometieran el futuro económico de sus compañías en el mercado norteamericano. Para Estados Unidos esto era inaceptable. Había una percepción, justificada o no, de que Canadá tendía a subvencionar a su sector exportador indebidamente. $Y$, desde el punto de vista estadounidense, una excepción simple-

\footnotetext{
${ }^{15}$ Fisher, "Politics of FrA trade disputes", International Perspectives, Vol, XVII, No5, septiembre/octubre 1988, pp. 17-18.

${ }^{16}$ Hart, op. cit, p. 54 , nota 48.
} 
mente suministraría a Canadá una "licencia" para subvencionar exportaciones a Estados Unidos. ${ }^{17}$

Finalmente los dos países adoptaron un sistema transnacional consistente en dos etapas. Primero, se mantendría la vigencia de las leyes remediales de comercio de ambos países, pero su interpretación en cuanto a su aplicación en el otro país estaría determinada por comités binacionales compuestos de ciudadanos de ambos países. En los casos que involucraran a subsidios y aranceles compensatorios, las decisiones de los comités serían obligatorias. En los otros casos, los comités solamente podrían recomendar decisiones, pero se esperaba que ambos países aceptarían en forma general las recomendaciones (Ver Cuadro 2). ${ }^{18}$ Se esperaba que, por lo menos, esto reduciría sustancialmente y, con suerte, eliminaría las consideraciones políticas y presiones del proceso terapéutico para el comercio. Es de notar, eso sí, que estos comités binacionales solamente fueron diseñados como una medida temporal. ${ }^{19}$

Para 1995, ambos países han acordado intentar el establecer definiciones mutuamente aceptables de subsidios permisibles y no permisibles dentro del contexto de su relación comercial bilateral. Este compromiso es un reto formidable, debido a que muchas veces es muy difícil diferenciar entre un subsidio y el legítimo ejercicio de la autoridad gubernamental en el área de gastos y entradas en busca de objetivos nacionales de importancia. Por ejemplo, las actividades gubernamentales realizadas con la intención de solucionar un problema doméstico importante pueden, como una consecuencia secundaria y no planificada, subsidiar algunas exportaciones. Como un caso puntual, se cree que la industria estadounidense de mic̀rocomputadores fue creada con el apoyo casi solitario al comienzo del Departamento de Defensa. Este apoyo indudablemente estuvo basado en consideraciones de seguridad nacional, pero sus beneficios para la potencialidad exportadora de la economía estadounidense en el sector de alta tecnología fue y sigue siendo sustancial. ${ }^{20}$

\footnotetext{
${ }^{17}$ Econascope, op. cit, p. 6.

${ }^{18}$ Fisher, op. cit., p. 8.

${ }^{19}$ Extemal Affairs Canada, op. cit, pp. 267-290.

${ }^{20}$ Econascopc, op. cit, p. 6.
} 
H. I. Stewart / El Acuerdo de Libre Comercio entre ...

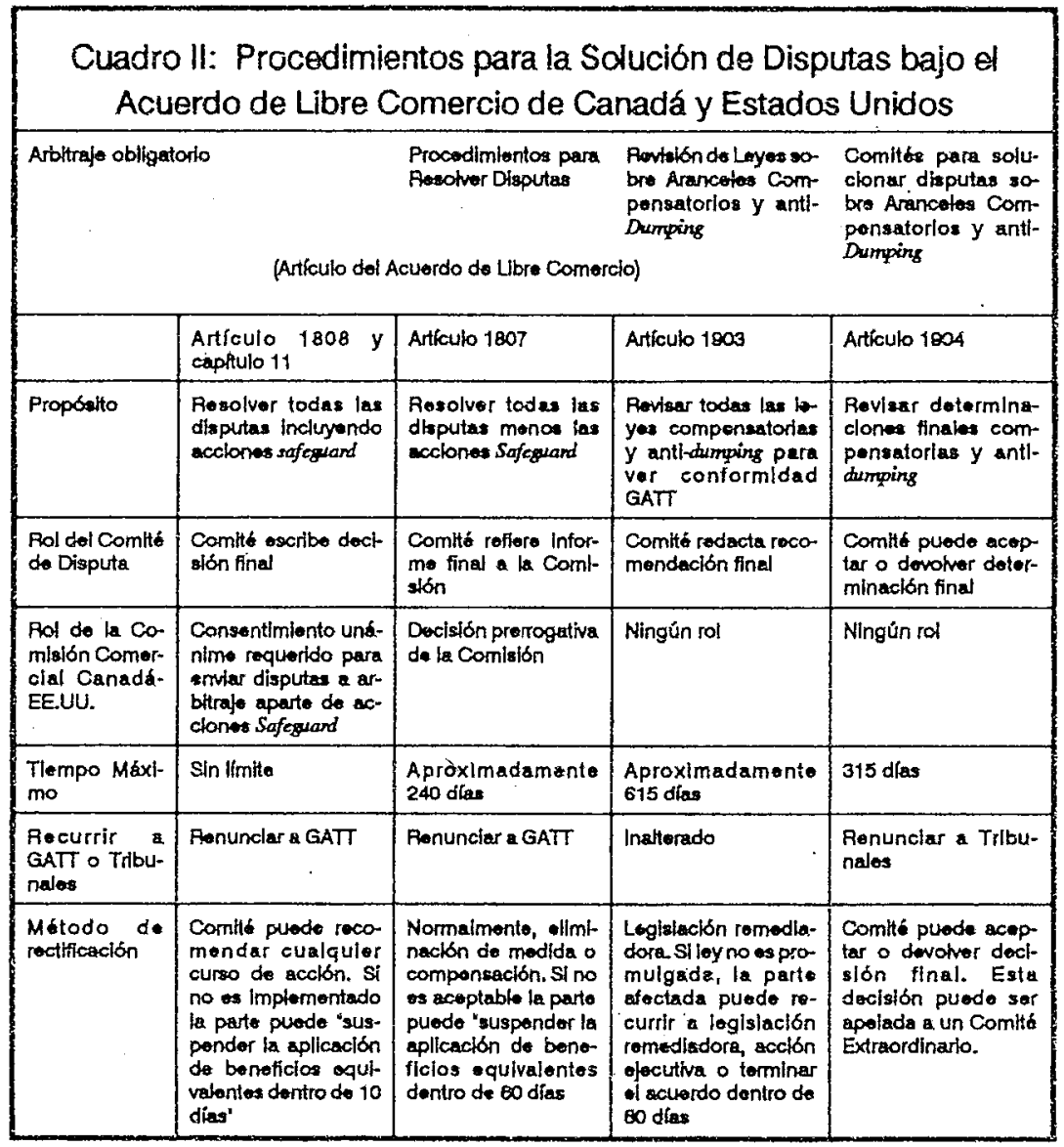

Cómo funcionará el Acuerdo en la práctica depende de la buena voluntad de los participantes, lo que es cierto en todos los tratados internacionales, dado que no se puede hacer cumplir el derecho internacional. Por supuesto, existe un temor de que tal vez Canadá ha apostado demasiado en algo impredecible, puesto que aceptando este mecanismo mucho más débil para solucionar disputas, se ha puesto vulnerable ante la presión de los Estados Unidos, apoyado por su mayor peso económico. Indudablemente los negociadores canadienses estaban conscientes de este peligro, pero siendo ellos oponentes acérrimos de los subsidios, consideraron que ésta era, dada la naturaleza del sistema estadounidense, probablemente la 
mejor solución que Canadá podía lograr. ${ }^{21}$ Sin embargo, hasta el momento, este mecanismo para solucionar disputas aparentemente ha funcionado en forma eficiente y razonablemente rápido para beneficio de ambos países. ${ }^{22}$

En esta área, NAFTA ha mejorado al sistema anterior, incluyendo reglas más claras sobre contenidos mínimos para que productos sean considerados de origen norteamericano. Esto incluye a automóviles, que fue uno de las áreas adonde hubo serios problemas entre ambos países. El contenido norteamericano para autos ahora subirá gradualmente, durante un período de 8 años, desde el.50\% existente hasta llegar a un $62.5 \%$, mientras que las reglas de origen más claras eliminaran las oportunidades para disputas. También, NAFTA tiene sistemas para la solución de disputas que, aunque basadas en el sistema actual del FTA, son mejoradas y más permanentes, y que serán aplicables a México. Todo èsto, establecerá una disciplina más fuerte sobre Estados Unidos con respecto a la imposición de restricciones fronterizas en contra no solamente de las importaciones desde Canadá y México, sino de cualquier país que se una al acuerdo en el futuro. $^{23}$

Finalmente, el FTA tuvo la intención de suministrar una base mejorada y más moderna para el manejo de la relación entre Canadá y Estados Unidos. Desde 1948, el GATT cumplió con esta función pero cada vez resultaba más inadecuado para ello. Durante los años setenta esta relación especial pasó por malos tiempos, cuando ambos gobiernos se distanciaron el uno del otro. Esto resultó en una crisis importante entre 1981 y 1982, cuando la llegada al poder en Washington de la administración conservadora de Ronald Reagan, unida al regreso al poder de un gobierno nuevamente vigorizado y nacionalista de Trudeau en Canadá, tuvo resultados desastrosos para la relación bilateral. En toda una gama de problemas, ambos gobiernos parecieron estar fuera de sincronización el uno con el otro.

La llegada al poder del Partido Conservador de Brian Mulroney en 1984, lo cambió todo. Un compromiso de revivir la largamente muerta relación especial con los Estados Unidos, fue una de las características determinantes del nuevo gobierno y el fundamento de

\footnotetext{
${ }^{21}$ Fisher, op. cit., pp. 17-20; Hart, op. cit., pp. 126-127; Netherton, "Hydro and the Free Trade Agreement" International Perspective, Vol. XVI, N21, enero/febrero de 1988, pp. 11-14.

${ }^{22}$ Econoscope, pp. 22-24; Free Trade Agreement: Second Year Review, pp. 21-24.

${ }^{23}$ The Royal Bank of Canada, Confidential Economics Weekly Digest, 20 de agosto de 1992, Montreal, Canadá.
} 
sus políticas. Se pensó que nuevas reglas más exigibles, combinadas con maquinaria institucional más sofisticada, pondría la relación en una base más predecible y menos confrontacional. ${ }^{24}$

Probablemente todavía es muy temprano para llegar a conclusiones definitivas sobre los efectos del FTA en Canadá. Esto es especialmente cierto, dado el hecho de que la recesión por la cual Canadá está pasando ahora, complica cualquier evaluación sobre el impacto del FTA en las industrias individuales. Las afirmaciones de que los cierres recientes de fábricas y el despido de personal són un resultado directo del FTA, son engañosas. La baja cíclica reciente en la industria manufacturera refleja una variedad de causas. Una de las más importantes, desde una perspectiva industrial, es la gran divergencia entre los costos de mano de obra en Canadá y Estados Únidos durante los últimos años.

Desde 1985, un dólar canadiense fuerte, aumentos de salarios más altos y un crecimiento de productividad más bajo, han significado que los costos de cada unidad de mano de obra canadiense en el sector manufacturero, han crecido aproximadamente un $43 \%$ más que en los Estados Unidos. Por ello está claro que la economía canadiense ahora tiene costos de mano de obra que no son competitivos en muchas de las industrias en las cuales compite internacionalmente. Aunque el FTA ha ayudado a incrementar esta competencia, la reducción en aranceles que ha ocurrido hasta ahora es insignificante cuando se la compara con la fuerte divergencia en costos de mano de obra.

Claramente, el sector manufacturero debe enfrentar los problemas que presentan la baja productividad y la inflación de salarios, si quiere sacar ventaja de las oportunidades que ofrece el libre comercio. Precisamente fue para solucionar estos problemas que se creo el FTA, con el propósito de establecer un ambiente que impulsara cambios estructurales de largo alcance. Muchos de los cierres de fábricas y lo ola de reestructuraciones y consolidaciones en el sector manufacturero canadiense durante los últimos años, tuvieron el objetivo de solucionar los problemas de productividad, eficiencia y competitividad. $^{25}$

Ciertamente, uno de los efectos más notables del FTA, ha sido el surgimiento de lo que parece ser el comienzo de actitudes inter-

\footnotetext{
${ }^{24}$ Hawes, "Mulroney and the Americans: a new era?", International Perspective, Vol. XVIII, NN1, enero/febrero 1989, pp. 9-12.

${ }^{25}$ Econoscope, op. cit, pp.15-21; Free-Trade Agreement: Second-year review, pp. 10-19.
} 
nacionales en el mundo de los negocios, donde las personas miran hacia afuera. El buen éxito de estos esfuerzos de racionalización y especialización solamente será evidente si los patrones del comercio canadiense se diversifican - no como el resultado de la reducción del comercio con los Estados Unidos, sino debido a un incremento del comercio a través del Atlántico y el Pacífico como resultado de una mayor competitividad y especialización. ${ }^{26}$

¿Qué puede aprender Chile de la experiencia canadiense? Para Chile, como lo fue para Canadá, la obtención de un mecanismo aceptable para la solución de disputas comerciales es absolutamente esencial. Chile, ya ha sido víctima de arbitrariedades estadounidenses, que se han extendido desde las órdenes de mercado que se aplican a la fruta chilena, por los intentos de forzar a Chile a firmar un mal llamado "acuerdo de restricción voluntario" que habría limitado las exportaciones de cobre a Estados Unidos, al caso de las uvas envenenadas. Sin la inclusión de un mecanismo que es por lo menos el equivalente del que está en el FTA o el NAFTA, negociar un acuerdo de libre comercio con los Estados Unidos sería una pérdida de tiempo y probablemente a largo plazo contraproducente.

Por esta razón creo que probablemente sería mejor para Chile aprovechar la cláusula de advenimiento de NAFTA, que tratar de negociar un acuerdo bilateral completamente nuevo con los Estados Unidos. Aunque no todos los artículos del NAFTA pueden ser convenientes para Chile (por ejemplo, NAFTA puede requerir cambios en las leyes chilenas sobre protección intelectual, especialmente patentes farmacéuticas, y medio ambiente y los sistemas de precios para productos agrícolas), en cualquier negociación directa con los Estados Unidos, Chile tendría que negociar sobre estos puntos, y es poco probable que obtendría mejores resultados que Canadá y México.

Otro factor desfavorable para Chile, es el artículo de NAFTA que establezca que el tratado "no hará nada para debilitar las leyes ambientales o disminuir el derecho de proteger la salud, seguridad y el medio ambiente de los norteamericanos y mantendrá el derecho que existe en el FTA de excluir cualquier producto que satisfaga los requisitos de salud o seguridad: "27 Lo que significa que el NAFTA no ofrecerá protección en contra de un caso similar a aquel de las uvas envenenadas. Pero, integrándose al NAFTA, Chile obtenđrá todas las

${ }^{26}$ Hart, op. cit, pp. 47, 132-136.

${ }^{27}$ The Globe and Mail, "Pact is sins by omission", 13 de agosto de 1992. 
ventajas que Canadá y México consiguieron. Además, el ahorro de tiempo negociador sería considerable, siendo que Chile atraparía tres países por el precio de uno.

Como descubrió Canadá durante sus negociaciones bilaterales, negociar directamente con los Estados Unidos no es un trabajo fácil. Esta nación es una potencia global, y como resultado persigue sus prioridades en una manera que hasta sus vecinos más cercanos tienen problemas para entender. Las negociaciones entre Canadá y Estados Unidos fueron noticias de primera plana en Canadá desde el comienzo al fin, pero fueron virtualmente desconocidas en los Estados Unidos . Como consecuencia, la atención que el problema recibió de los funcionarios y políticos en los dos países fue asimétrica, un hecho de poco.efecto en Washington pero de gran importancia en Ottawa. Desde el punto de vista canadiense, el lado estadounidense destinó recursos inadecuados a las negociaciones. Muchas veces no estaba preparado para las sesiones de negociación, no siempre había pensado sus posiciones a fondo, muchas veces le importaba más el establecimiento de precedentes globales que el examen de los méritos de problemas en particular, y estaba siempre mirando sobre su hombro preguntándose que pensaría el Congreso. En resumen, los Estados Unidos aunque estaba entusiasta acerca de la idea de un acuerdo, no estaba preparado para proseguir con los necesarios recursos y el compromiso con los detalles. ${ }^{28}$

No hay nada simple cuando se negocia con los Estados Unidos. El compromiso político del Presidente no es suficiente. También, hay que destinar esfuerzos àl cultivo del entusiasmo y apoyo más abajo, entre otros jugadores políticos y aun burocráticos. Es muy fácil para los extranjeros el sobreestimar el poder del Presidente. Para asegurarse un apoyo amplio, los gobiernos extranjeros tienen que demostrar por qué las negociaciones son de interés para los Estados Unidos y deben desarrollar un fuerte grupo de presión (lobby) en la política doméstica estadounidense, dispuestos a cabildear por un acuerdo. Cuando no se cultiva este tipo de apoyo las negociaciones tienden a fracasar o a ser no satisfactorias. Finalmente, para concentrar la mente estadounidense, las negociaciones necesitan una fecha límite firme e inalterable, o no pueden nunca despegar de la tierra.

También, es necesario cultivar cuidadosamente al Congreso dada la excesiva preocupación que se le da a las opiniones congresa-

${ }^{28}$ Hart, op. cit., pp. $87-88$. 
les, lo que ha resultado ser algo irritante en todas las recientes negociaciones con los Estados Unidos. Este es un reflejo de la manera en que la forma estadounidense de gobierno ahora está dominada por los intereses especiales. Esto significa que el gobierno extranjero no solamente debe negociar con la administración, sino que también debe destinar tiempo a desarrollar apoyo en el Congreso. No se puede esperar que la administración lo haga todo por uno. ${ }^{29}$

Dada la ansiedad que cualquier pequeño país siente normalmente cuando está negociando con una potencia global, es necesario que el empuje y deseo para el acuerdo se origine en el país más pequeño. Pero la necesidad de desarrollar grupos de presión en los Estados Unidos y cultivar el Congreso, dará la impresión equivocada que el país más pequeño desea desesperadamente un àcuerdo y firmará casi cualquier cosa. En el caso de Chile, esto pođría significar que Estados Unidos nos presente un acuerdo como el que firmara con México, sobre una base de "tómelo o déjelo". Entonces se necesitará un acto muy habilidoso de balanceo entre el deseo de llegar a un acuerdo y la habilidad de mantenerse apartado acerca del resultado final, todo lo cual será mucho más difícil debido a la necesidad de manejar el debate doméstico. Afortunadamente para Chile, no tenemos que enfrentar los problemas que significa compartir una frontera común con los Estados Unidos.

\section{BIBLIOGRAFIA}

Econoscope, "Free Trade Agreement: One-year Retrospective", Montreal, The Royal Bank of Canada, 1990.

Econoscope, "Free Trade Agreement: Second-year Review", Montreal, The Royal Bank of Canada, 1991.

Econoscope, "Mexico-U.S. Trade Talks: Why Canada Should Get Involved", Montreal, The Royal Bank of Canada, 1990.

The Economist, "The Business of the American Hemisphere", 24 de agosto de 1991 y "Shoot-out at Jackson Hole", 31 de agosto de 1991.

External Affairs Canada, The Text of the Canada-U.S. Free Trade Agreement, Ottawa, Department of External Affairs, 1988.

Farr, David, "Inner Meaning of Free Trade", International Perspectives, Vol. XVII, N²4, julio/agosto 1988.

\footnotetext{
${ }^{29}$ Ver David Leyton-Brown, "The Domestic Policy-Making process in the United States"; Allen E. Gotlieb, "The Canada-United States Relationship", en: D. H. Flaherty y W. R. McKercher, Southern Expasure: Canadian Perspectives on the United States.
} 
Fisher, Bruce H., "Politics of FTA Trade Disputes", International Perspectives, Vol. XVII, №5, septiembre/octubre 1988.

Flaherty, D. H. y McKercher, W. R., Southem Exposure: Canadian Perspectives on the United States, Toronto: McGraw-Hill Ryerson, 1986.

The Globe and Mail, "North America agrees to deal" \& "Pact is sins by omission", 13 de agosto de 1992.

Hart, Michael, A North American Free Trade Agreement: The Strategic Implications for Canada. Halifax: The Institute for Research on Public Policy, 1990.

Hawes, Michael K., "Mulroney and the Americans: a New Era?", International Perspectives, Vol. XVII, N'1, enero/febrero 1989.

Netherton, Alex, "Hydro in the Free Trade Agreement", International Perspectives, Vol. XVII, NN1, enero/febrero 1988.

The Royal Bank of Canada, Confidential Economics Weekly Digest, 20 de agosto de 1992, Montreal, Canadá.

Thomson, Dr. A. J., "Adjusting to Free Trade Challenges", Econoscope, Montreal, The Royal Bank of Canada, 1989.

Wilson, Michael H., Canada's Economic Prospects: Looking Ahead to the 1990s. Ottawa: Department of Finance, 1988. 